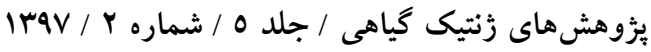

بررسى تنوع زنتيكى تعدادى از زرم يلاسمهاى بادام زمينى (Arachis hypogea) با استفاده از صفات مورفولوزيكى

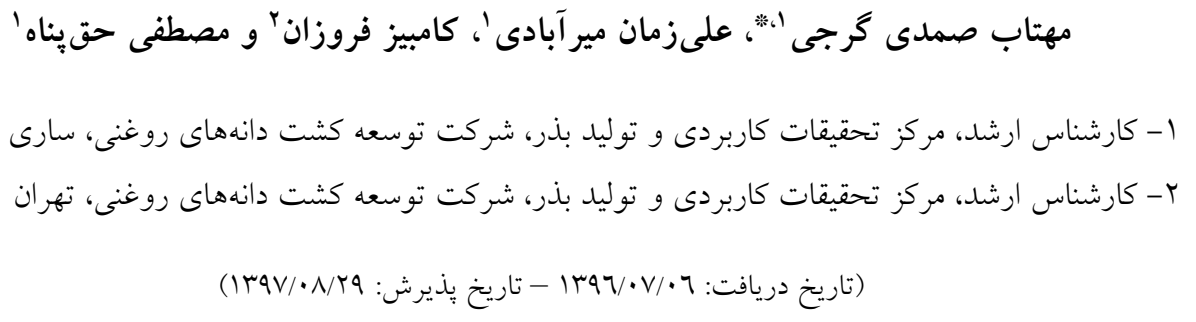

اين آزمايش به منظور ارزيابى تنوع زنتيكى تعدادى از زرم بلاسمهاى وارداتى بادامزمينى از بانك بذر كثور استراليا در مركز

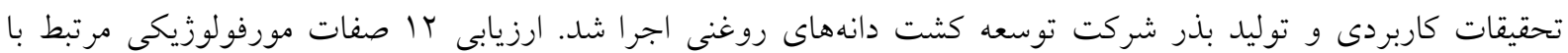

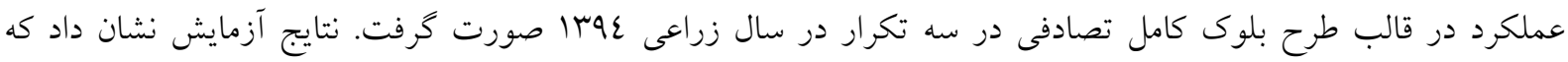

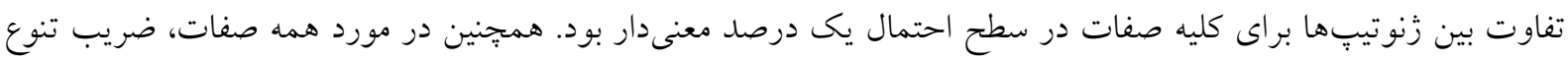

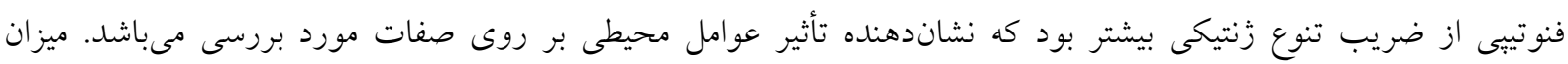

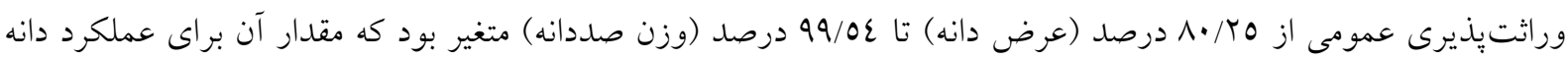

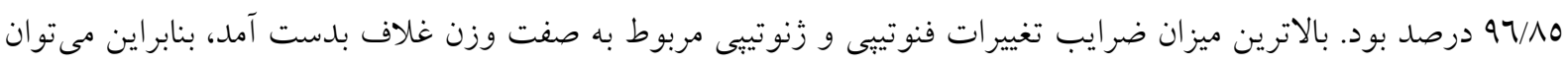

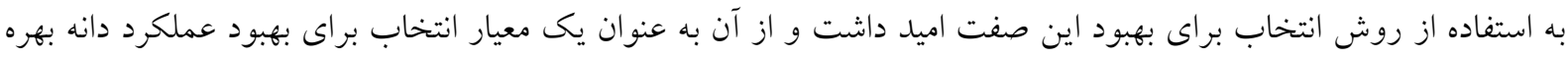

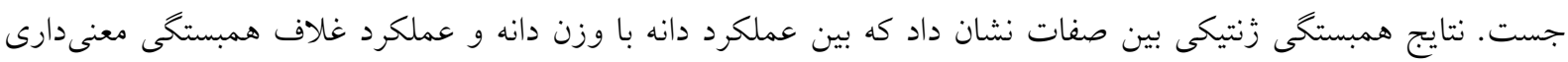

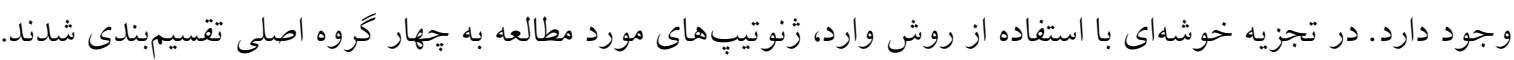
وازگًان كليدى: بادامزمينى، تجزيه خوشهاى، تنوع زنتيكى، صفات مورفولوزيكى 
زنتيكى، افزايش كارآيى مجموعههاى زنتيكى در

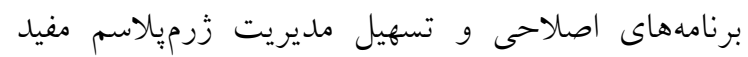
هستند ( Dwivedi et al., 2001; Hilu and Stalker,

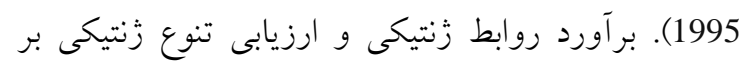

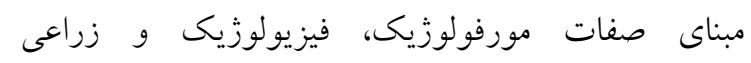

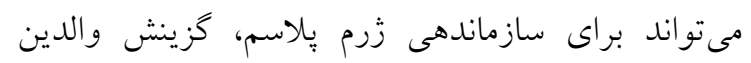

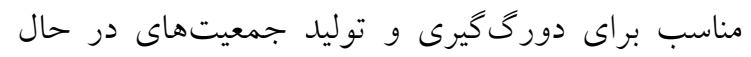
تفرق سودمند باشد (Holbrook and Dong, 2005).

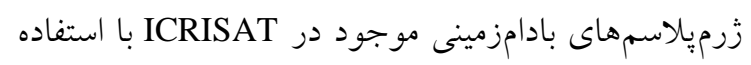

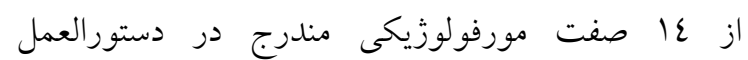
اندازهخيرى و ثبت صفات بادامزمينى مورد مطالعه قرار كرفت و يك كلكسيون مركزى كه نماينده كلكسيون اوليه

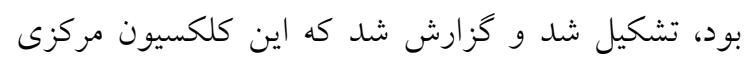

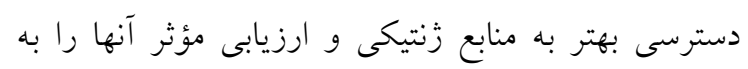

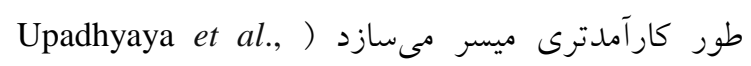

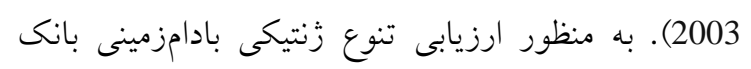

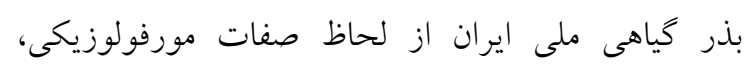

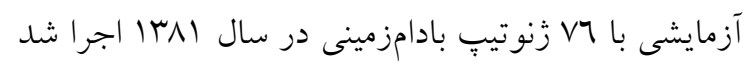
كه نتايج حاكى از تشابه بالاى نمونههاى مورد مطالعه با بامنيا

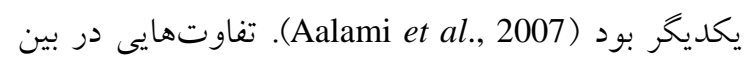

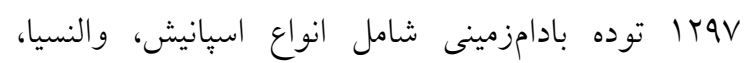

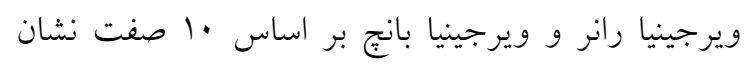

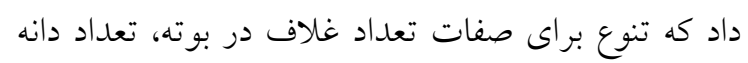

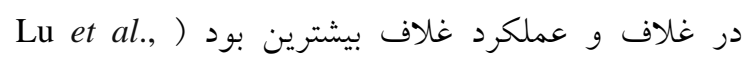

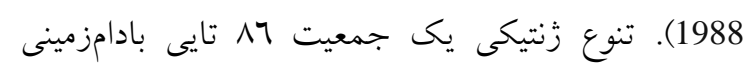

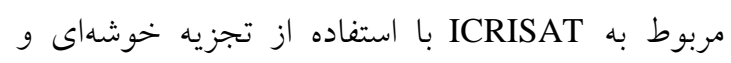

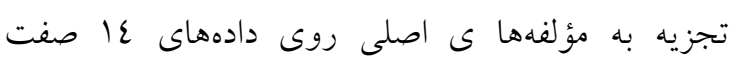

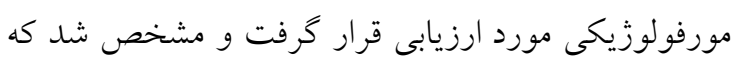

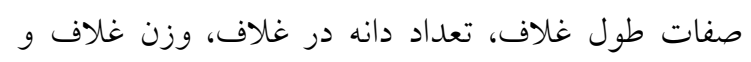

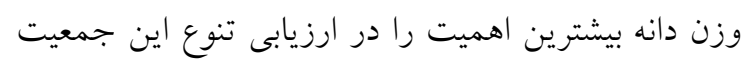

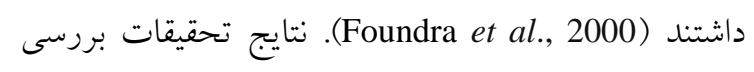
Vo نمونه بادامزمينى مربوط به بانك زن كياهى ملى ايران در موسسه تحقيقات كشاورزى كيلان نشان داد تفاوت ميان زنوتيبٍا براى كليه صفات در سطح احتمال 1

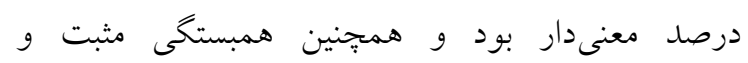




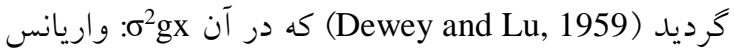
زنتيكى صفت (x)، Covgxy

$r g=\frac{\operatorname{Cov}_{g x y}}{\sqrt{\left(\sigma_{g x}^{2} \times \sigma_{g y}^{2}\right)}}$

(1) (1)

اجزاى واريانس محيطى، زنتيكى و فنوتيبى براساس اميد

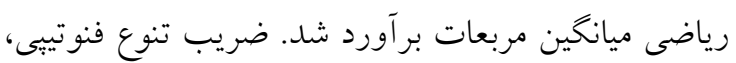

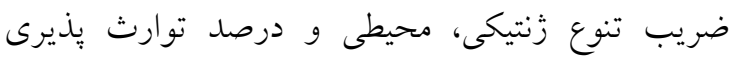
عمومى (Hb) هر صفت با استفاده از روابط زير محاسبه كرديد (Burton and Devane, 1953).
$V E=\frac{M S e}{r}$
رابطه (T)
$V P=V G+V E$
رابطه (r)
$V G=\frac{M S t-M S e}{r}$
رابطه (ع)
$C V P=\frac{\sqrt{V P}}{\bar{X}}$
رابطه (0)
$C V G=\frac{\sqrt{V G}}{\bar{X}}$
رابطه (7)
$C V E=\frac{\sqrt{V E}}{\bar{X}}$
رابطه (V)
$H b=\frac{V G}{V P}$
رابطه (1)

در اين معادلات، VG واريانس زنوتييى، VE واريانس محيطى، VP واريانس فنوتيبى، MSe واريانس اشتباه آزمايش، r تعداد تكرار، CVP ضريب تنوع فنوتيبى، CVG ضريب تنوع زنتيكى، CVE ضريب تنوع محيطى و ميانخين كل براى هر صفت مىباشد. تجزيه خوشهاى مبتنى بر روش وارد بر اساس مجذور فاصله اقليدسى انجام كرفت. همجهنين به منظور مقايسه ميانخين گروههاى حاصل از تجزيه خوشهاى از نظر صفات مورد ارزيابى، تجزيه واريانس بر اساس طرح كاملا تصادفى نامتعادل (به طورى كه گروهها به عنوان تيمار و زَنوتيِهاى درون آن ها به عنوان تكرار منظور كرديد)، از روش حداقل دامنه معنىدار (دانكن) استفاده شد. تجزيههاى آمارى با استفاده از نرم افزار SPSS v23 و و

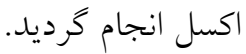

معنى دارى بين عملكرد دانه با وزن غلاف در بوته، تعداد دانه در بوته، تعداد غلاف در بوته و وزن دانه وجود داشت (Aalami et al., 2007). ابراهيمى و همكاران (Ebrahimi et al., 2016) وراثتيذيرى و كروهبندى VT لاين جو هايلوئيد مضاعف شاخصهاى مرتبط با جوانهزنى در شرايط تنش شورى را مورد ارزيابى قرار دادند و بيان كردند زنوتيبٍهاى مورد

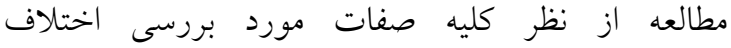
معنى دارى با يكديخر دارند و همجنين همبستخى بالا و معنى دارى بين صفت ميانخين جوانهزنى روزانه و درصد جوانهزنى نهايى وجود داشت. هدف از مطالعه حاضر، بررسى تنوع زنتيكى بين VT زنوتيتٍ بادامزمينى، محاسبه وراثتيذيرى بعضى صفات مرتبط با عملكرد و بررسى روابط همبستخى بين صفات جهت استفاده از آنها بهعنوان شاخص هاى انتخاب در برنامههاى بهنزادى بود. مواد و روش مها اين آزمايش به منظور ارزيابى لr زنوتيبٍ بادامزمينى وارداتى از بانك بذر كشور استراليا در مجتمع تحقيقات كاربردى و توليد بذر (تكاتو) شركت توسعه كشت دانهاى روغنى در سال زراعى ع9 اجرا گرديد. از هر زنوتيبٍ r خط س مترى در هر بلوى در قالب طرح بلوى كامل تصادفى در سه تكرار كشت كرديد. فاصله بين تيمارها يك متر، فاصله بين بلوكها دو متر و فاصله بين بوتهها در هر رديف ·r سانتىمتر در نظر كرفته شد. براى

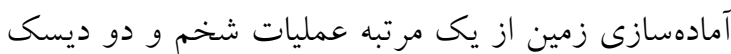
عمود بر هم استفاده گرديد. در طول مراحل داشت عمليات وجين و خاكدهى ياى بوتهها، كوددهى و آبيارى و به ترتيب در ما، r و ب نوبت صورت گرفت. يس از برداشت در نهايت نسبت به محاسبه صفات تعداد غلاف، وزن دانه، وزن دانه در غلاف، وزن غلاف، نسبت وزن دانه به غلاف، وزن صد دانه، طول دانه، عرض دانه، ميانخين نسبت طول به عرض دانه، عملكرد غلاف، عملكرد دانه و عملكرد كل اقدام گرديد. تجزيه واريانس داده صورت گرفت و ضرايب همبستخى زنوتييى(rg) بين صفات مختلف طبق رابطه زير محاسبه 
اثر است. مطالعات انجام شده بر روى به لاين در حال تفرق نسل F3 نيز نشان داد كه صفت وزن صد دانه وراثت يذيرى عمومى بالايى (VI/UT)

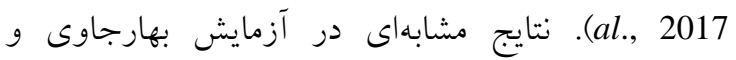
همكاران (Bhargavi et al., 2017) نيز مشاهده شد. كمترين ميزان وراثت يذيرى در صفت عرض دانه (1/T0/) مشاهده شد. ضرايب همبستخى زنوتيبى بدست

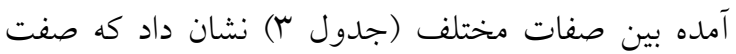
وزن صد دانه و عملكرد غلاف همبستخى مثبت و معنى دار با عملكرد دانه دارد. همجنين بين صفات وزن دانه با تعداد غلاف و طول دانه با وزن صد دانه همبستى هاري مثبت و معنىدار مشاهده شد. همبستخى بين صفات

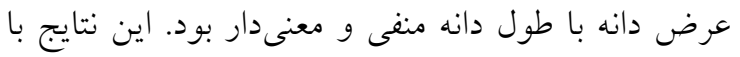
بررسى هاى اعلمى و همكاران (Y.V.V) مطابقت داشت.

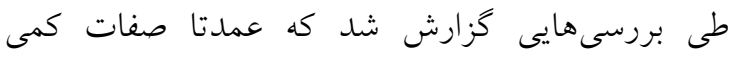
مربوط به دانه مانند وزن و تعداد دانه با صفات مربوط به به تهرئ

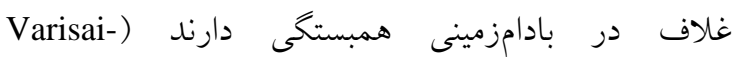
.(Muhammad et al., 1975; Soomro and Larik, 1981 تجزيه خوشهاى با استفاده از روش وارد مبتنى بر مجذور

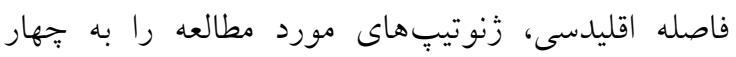

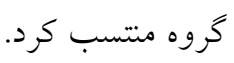
نتايج تجزيه واريانس صفات كمى مورد ارزيابى در جدول

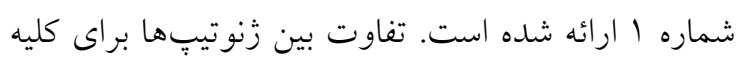

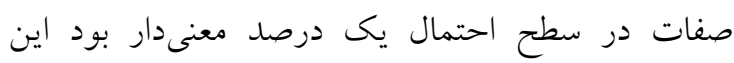

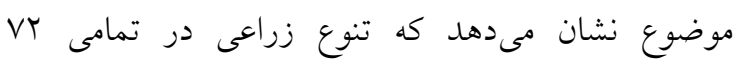

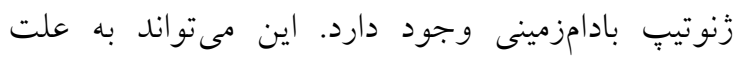

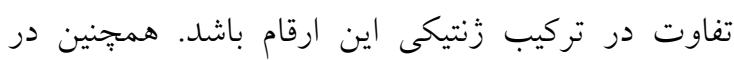

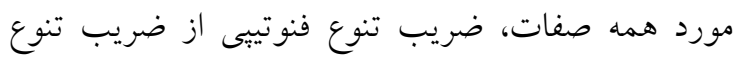

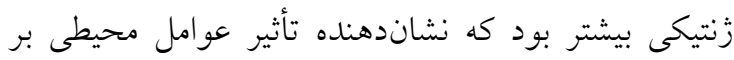

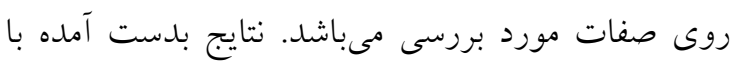
مطالعات نيكوسرشت و نجفيان ( Nikoseresht and مطابقت داشت. هم:جنين بيشترين ميزان (Najafian, 2016

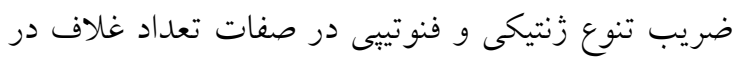

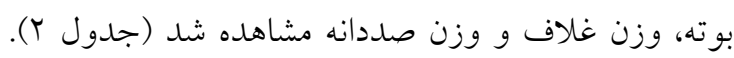

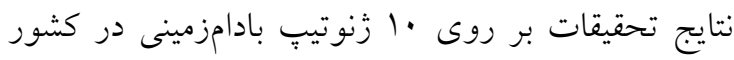

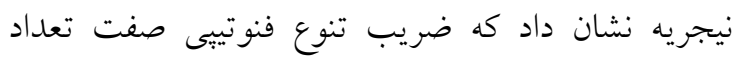
غلاف در بوته بسيار بالاست (Vange and Maga, 2014). وراثت يذيرى تعداد غلاف و وزن صددانه داراى بيشترين مقدار و به ترتيب برابر 99/TV و 99/0 درصد بود.

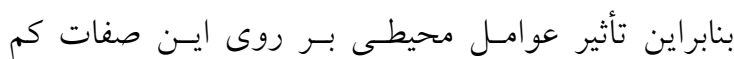

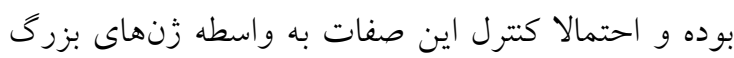

جدول ا - تجزيه واريانس صفات كمى مورد ارزيابى در زنوتيبهاى بادام زمينى

Table 1. Analysis of variance of quantitative traits in peanut genotypes

\begin{tabular}{|c|c|c|c|c|c|c|c|c|}
\hline \multirow{4}{*}{ منابع تغييرات } & \multirow{4}{*}{ S.O.V } & \multirow{4}{*}{$\begin{array}{l}\text { آزادى } \\
\text { df } \\
\text { df }\end{array}$} & \multicolumn{6}{|c|}{ ميانخين مربعات (MS) } \\
\hline & & & & & & & نسبت وزن دانه & وزن صد \\
\hline & & & تعداد علاف & وزن دانه & وزن دانه و علاف & وزن غلاف & به غلاف & دانه \\
\hline & & & $\begin{array}{c}\text { Pod } \\
\text { No./Plant }\end{array}$ & $\begin{array}{l}\text { Grain } \\
\text { weight }\end{array}$ & $\begin{array}{c}\text { Grain and Pod } \\
\text { weight }\end{array}$ & Pod weight & $\begin{array}{c}\text { Grain weight/ } \\
\text { Pod weight }\end{array}$ & $\begin{array}{c}100 \text { grain } \\
\text { weight }\end{array}$ \\
\hline ت تكرار & Replication & 2 & 0.873 & 0.044 & 0.297 & 0.433 & 0.011 & 54.992 \\
\hline تيمار & Genotype & 71 & $108.781^{* *}$ & $21.611^{* *}$ & $50.045^{* *}$ & $13.653^{* *}$ & $0.446^{* *}$ & $143.009^{* *}$ \\
\hline خطا & Error & 142 & 0.796 & 0.562 & 0.838 & 0.804 & 0.085 & 0.653 \\
\hline ضريب & C.V. (\%) & & 17.39 & 10.41 & 10.79 & 18.76 & 19.88 & 18.12 \\
\hline
\end{tabular}




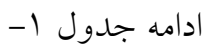

Table 1. Continued

\begin{tabular}{|c|c|c|c|c|c|c|c|c|}
\hline \multirow[b]{2}{*}{ منابع تغييرات } & \multirow[b]{2}{*}{ S.O.V } & \multirow[b]{2}{*}{$\begin{array}{l}\text { درجادى } \\
\text { df }\end{array}$} & \multicolumn{6}{|c|}{ ميانخين مربعات (MS) } \\
\hline & & & $\begin{array}{c}\text { طول دانه } \\
\text { Grain length }\end{array}$ & $\begin{array}{c}\text { عرض دانه } \\
\text { Grain width }\end{array}$ & $\begin{array}{c}\text { نسبت طول به } \\
\text { Grain length/ Grain } \\
\text { weight } \\
\text { wiانه }\end{array}$ & عملكرد غالاف & عملكرد دانه & عملكرد كل \\
\hline تكرار & Replication & 2 & 0.774 & 1.461 & 0.005 & 1191.271 & 3566.071 & 4377.835 \\
\hline تيمار & Genotype & 71 & $16.614^{* *}$ & $3.302^{* *}$ & $0.042^{* *}$ & $43696.987^{* *}$ & $25477.935^{* *}$ & $129464.447^{* *}$ \\
\hline خطا & Error & 142 & 1.506 & 0.0652 & 0.008 & 1444.551 & 802.685 & 2921.546 \\
\hline ضغريب & C.V. $(\%)$ & & 10.80 & 6.94 & 10.38 & 20.30 & 20.72 & 23.13 \\
\hline
\end{tabular}

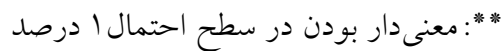

**: Significant at $1 \%$ probability level

جدول r - قابليت وراثت يذيرى بعضى از صفات زراعى بادامزمينى

Table 2. The heritability of some agronomic traits in peanut

\begin{tabular}{|c|c|c|c|c|c|c|c|c|}
\hline \multirow{2}{*}{ صفات } & \multirow{2}{*}{ Traits } & \multicolumn{3}{|c|}{$\begin{array}{l}\text { برآورد اجزاى واريانس } \\
\text { Variance components }\end{array}$} & \multicolumn{3}{|c|}{$\begin{array}{c}\text { ضريب تنوع } \\
\text { Coefficient of variation of }\end{array}$} & \multirow{2}{*}{ 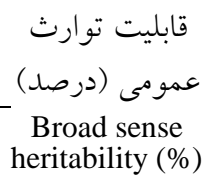 } \\
\hline & & $\begin{array}{c}\text { محيطى } \\
\text { Environment }\end{array}$ & $\begin{array}{c}\text { فنوتييى } \\
\text { Phenotypic }\end{array}$ & $\begin{array}{l}\text { زنتيكى } \\
\text { Genotypic }\end{array}$ & $\begin{array}{c}\text { محيطى } \\
\text { Environment }\end{array}$ & $\begin{array}{c}\text { فنو تيبى } \\
\text { Phenotypic }\end{array}$ & $\begin{array}{c}\text { زنتيكى } \\
\text { Genotypic }\end{array}$ & \\
\hline تعداد غاف & Pod No./Plan & 0.27 & 36.26 & 36.00 & 1.49 & 17.38 & 17.32 & 99.27 \\
\hline وزن دانه (كرم) & $\begin{array}{c}\text { Grain weight } \\
\text { (gr) }\end{array}$ & 0.19 & 7.20 & 7.02 & 1.65 & 10.22 & 10.09 & 97.40 \\
\hline غلاف (گرم) دانه و & $\begin{array}{l}\text { Grain and } \\
\text { Pod weight } \\
\text { (gr) }\end{array}$ & 0.28 & 16.68 & 16.40 & 1.38 & 10.69 & 10.60 & 98.33 \\
\hline وزن غلاف & $\begin{array}{l}\text { Pod weight } \\
\text { (gr) }\end{array}$ & 0.27 & 4.55 & 4.28 & 4.33 & 17.86 & 17.33 & 94.11 \\
\hline نسبت وزن دانه & $\begin{array}{l}\text { Grain weight } \\
\text { / Pod weight }\end{array}$ & 0.03 & 0.15 & 0.12 & 7.44 & 17.05 & 15.34 & 80.94 \\
\hline 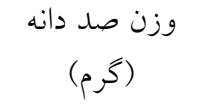 & $\begin{array}{c}100 \text { grain } \\
\text { weight (gr) }\end{array}$ & 0.22 & 47.67 & 47.45 & 1.22 & 18.07 & 18.03 & 99.54 \\
\hline طول دانه & $\begin{array}{l}\text { Grain length } \\
(\mathrm{mm})\end{array}$ & 0.50 & 5.54 & 5.04 & 3.01 & 10.00 & 9.54 & 90.94 \\
\hline عرض دانه & $\begin{array}{l}\text { Grain width } \\
\quad(\mathrm{mm})\end{array}$ & 0.22 & 1.10 & 0.88 & 2.62 & 5.89 & 5.28 & 80.25 \\
\hline عرضت طول دانه به & $\begin{array}{l}\text { Grain length/ } \\
\text { Grain weight }\end{array}$ & 0.00 & 0.01 & 0.01 & 3.90 & 8.94 & 8.04 & 80.95 \\
\hline عملكرد غلاف & $\begin{array}{l}\text { Pod yield } \\
\text { (gr) }\end{array}$ & 481.52 & 14565.66 & 14084.15 & 3.60 & 19.79 & 19.46 & 96.69 \\
\hline عملكرد دانه & $\begin{array}{l}\text { Grain yield } \\
\text { (gr) }\end{array}$ & 267.56 & 8492.65 & 8225.08 & 1.61 & 9.05 & 8.90 & 96.85 \\
\hline 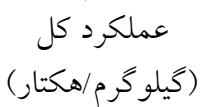 & $\begin{array}{c}\text { Total yield } \\
(\mathrm{kg} \backslash \mathrm{ha})\end{array}$ & 973.85 & 43154.82 & 42180.97 & 7.64 & 50.83 & 50.26 & 97.74 \\
\hline
\end{tabular}




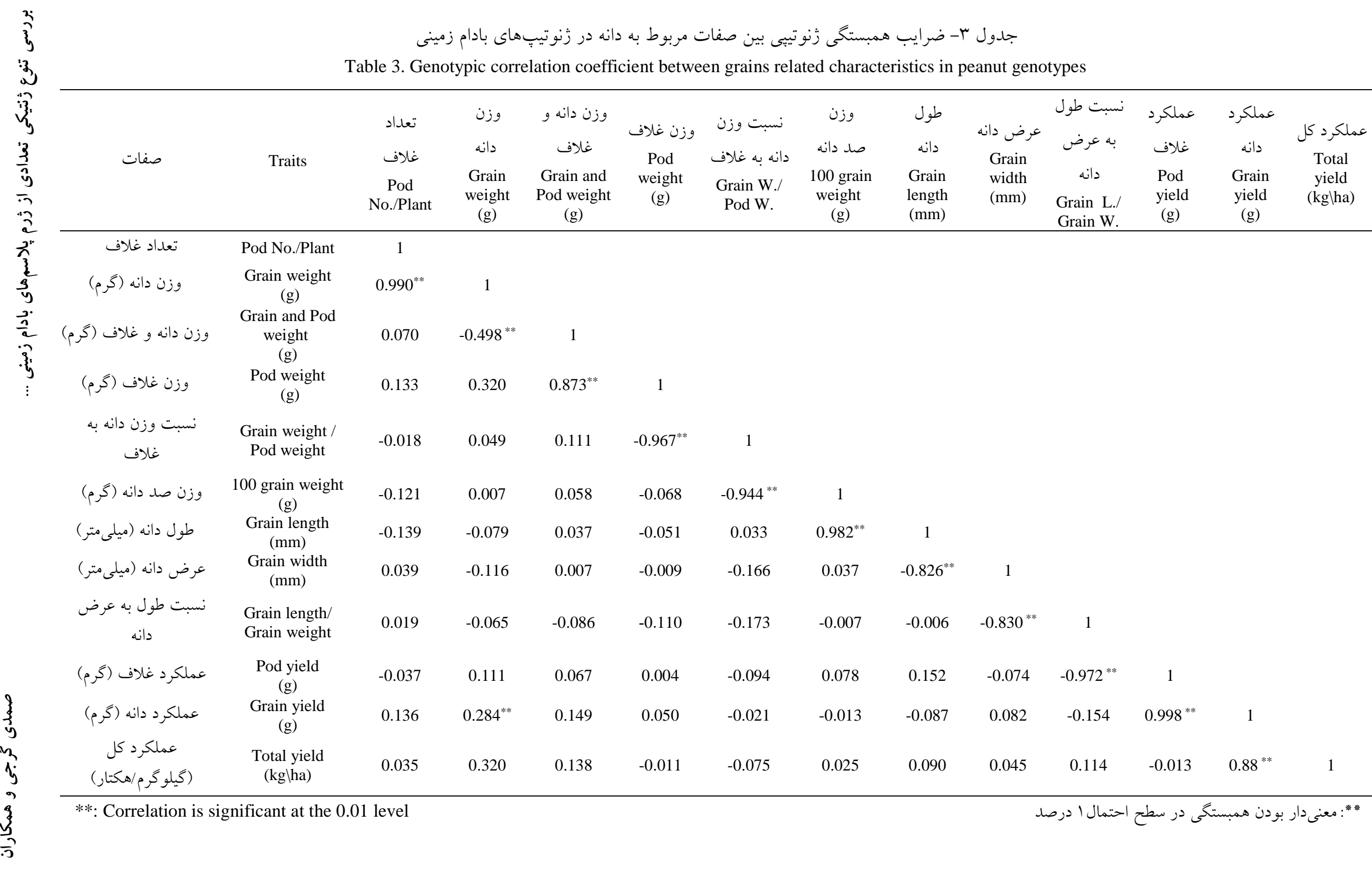


طول به عرض دانه نسبت به ميانكين كل زنوتيبها بود.

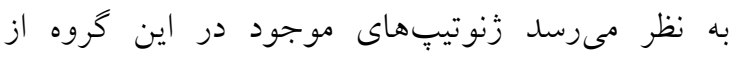
اهميت بالاترى برخوردار باشند. البته قابل ذكر است كه

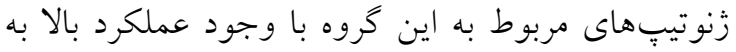

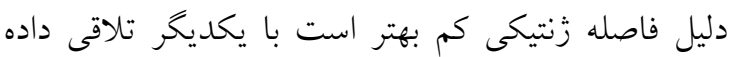
نشوند و در برنامههاى بهنزادى جهت ايجاد رقم هيبريد و دستيابى به حداكثر هتروزيس بهتر است از افراد مربوط به به به بهري

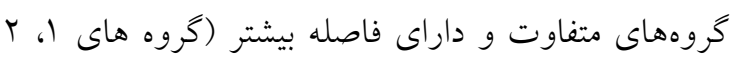

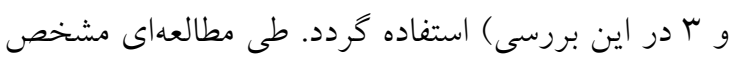

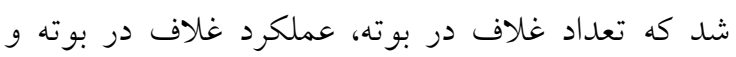
وزن صد دانه يارامترهاى بسيار هزم عملكرد هستند

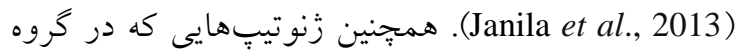
سوم قرار كرفتند كمترين ميزان عملكرد غلاف و دانه را توليد كردند و از نظر ساير خصوصيات مرتبط با عملكرد

$$
\text { نيز داراى مقادير كمترى بودند. }
$$

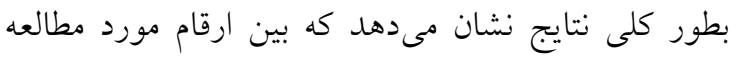

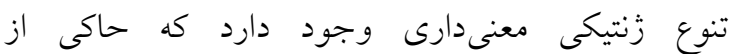

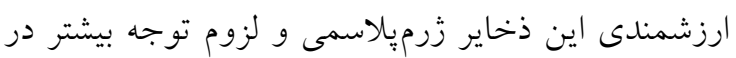

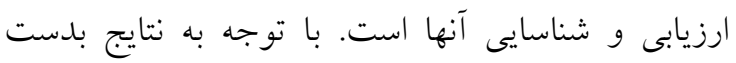

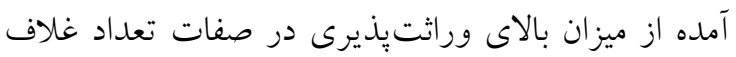
و وزن صد دانه كه بيانكر اثر افزايشى زنها در كنترل اين صفات است، مىتوان به روش انتخاب براى بهبود اين

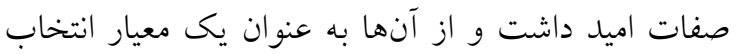

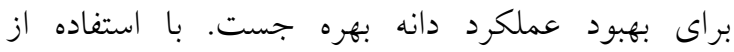

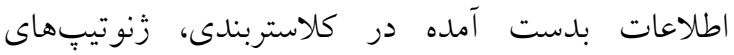

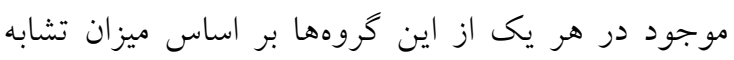
صفات مختلف دستهبندى شدهاند. بنابراين در برنامههاى بلهنزادى با توجه به هدف اصلاحى مورد نظر مى توان از

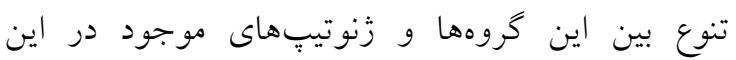
كروهها استفاده نمود و با انجام تلاقى بين آنها امكان

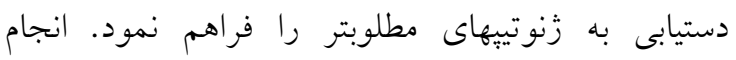

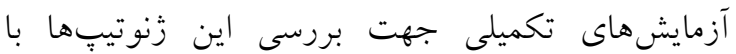

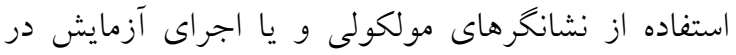
شرايط آب و هوايى ديخر براى تفكيك و تمايز بهتر نمونهاى موجود و تعيين والدين مناسب براى برنامههاى

$$
\text { دورى گيرى ييشنهاد مى شودد. }
$$

كروه اول شامل Y Y نمونه، گروه دوم IV نمونه، گروه

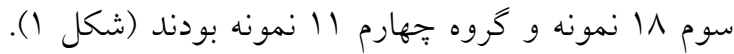
هر كدام از گروهها به زير خروههايى تقسيم شدند. افرادى

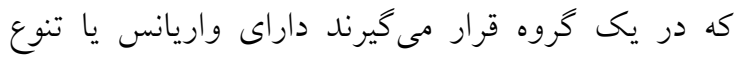
كمترى نسبت به واريانس و تنوع موجود بين كرونه فرونها

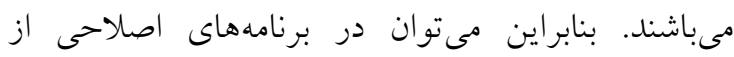

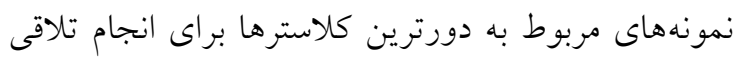

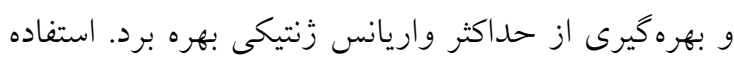

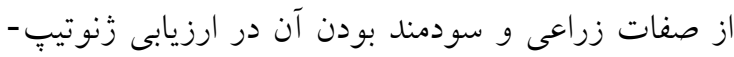

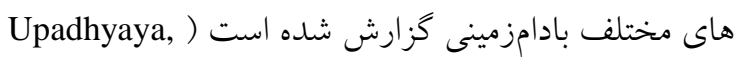

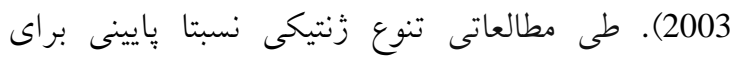

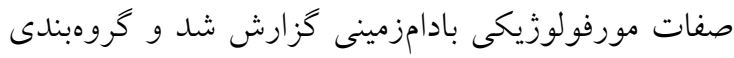
جندان مشخصى از دندروكرام حاصله بدست نيامد و بيان

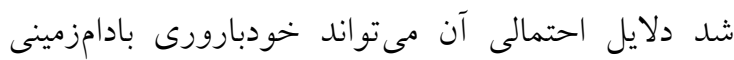
باشد ( Badigannavar et al., 2002; Dwivedi et al., بالى

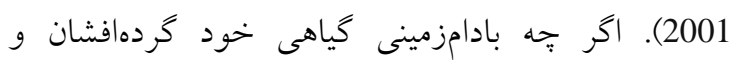
داراى تنوع محدود است، اختلاف آمارى معنىدار ميان

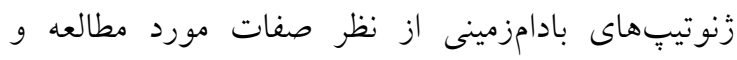

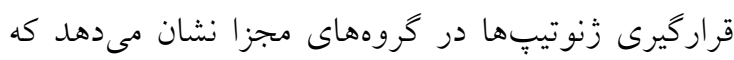
تا حد زيادى تنوع زنتيكى در ميان انواع بادامزمينى درونى مورد

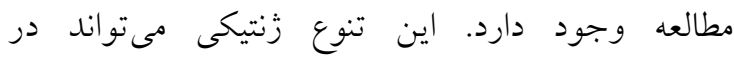
برنامهاى بهبود گونههاى جديد با ويزَّىهاى مورد نظر مورد استفاده قرار كيرد.

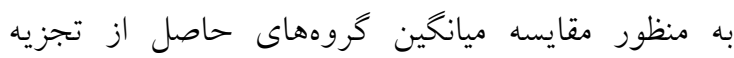
خوشهاى از نظر صفات مورد ارزيابى، تجزيه واريانس بر بر برائه اساس طرح كاملا تصادفى نامتعادل به طورى كه كروهها

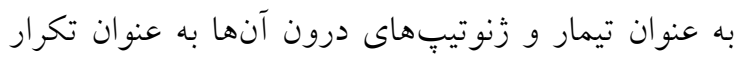
منظور كرديد، از روش حداقل داقل دامنه معنى دار (دانكن)

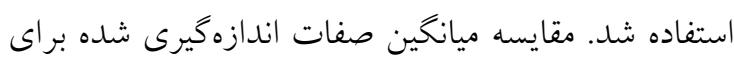

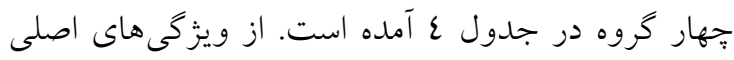

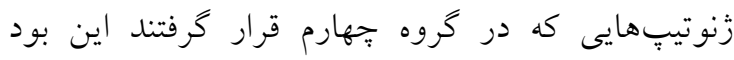

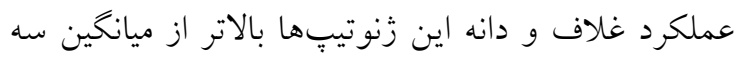

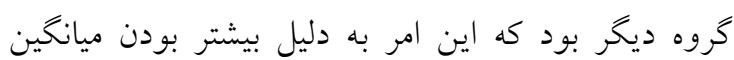

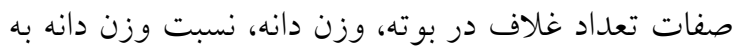
وزن غلاف، وزن غلاف، وزن صد دانه، طول دانه و نسبت 


$$
\text { جدول ع- ميانخين صفات در گرووها }
$$

Table 4. Mean of traits in different clusters

\begin{tabular}{|c|c|c|c|c|c|c|}
\hline صفات & Traits & $\begin{array}{l}\text { ميانخين } \\
\text { Total } \\
\text { mean }\end{array}$ & $\begin{array}{c}\text { كاسانگين } \\
\text { كاستر اول } \\
\text { First } \\
\text { cluster } \\
\text { mean }\end{array}$ & $\begin{array}{c}\text { ميانخين } \\
\text { كاستر دوم } \\
\text { Second } \\
\text { cluster mean }\end{array}$ & $\begin{array}{c}\text { كيانكين } \\
\text { كاستر سوم } \\
\begin{array}{c}\text { Third cluster } \\
\text { mean }\end{array}\end{array}$ & $\begin{array}{l}\text { كيانخين } \\
\text { كلاستر جهارم } \\
\text { Fourth } \\
\text { cluster mean }\end{array}$ \\
\hline تعداد غلاف & Pod No./Plant & 34.69 & $35.69 \mathrm{a}$ & $34.10 \mathrm{a}$ & $32.59 \mathrm{a}$ & $36.36 \mathrm{a}$ \\
\hline وزن دانه (گرم) & $\begin{array}{l}\text { Grain weight } \\
(\mathrm{g})\end{array}$ & 26.43 & $26.32 b$ & $26.12 b$ & $25.14 b$ & $28.14 \mathrm{a}$ \\
\hline وزن دانه و غلاف & $\begin{array}{l}\text { Grain and Pod weight } \\
(\mathrm{g})\end{array}$ & 38.60 & $37.91 \mathrm{~b}$ & $39.40 \mathrm{ab}$ & $35.28 \mathrm{c}$ & $41.80 \mathrm{a}$ \\
\hline وزن غلاف (كرم) & $\begin{array}{l}\text { pod weight } \\
\text { (g) }\end{array}$ & 12.17 & $11.59 \mathrm{~b}$ & $13.27 \mathrm{a}$ & $10.15 \mathrm{c}$ & $13.66 \mathrm{a}$ \\
\hline نسبت وزن دانه به & $\begin{array}{c}\text { Grain weight/ Pod } \\
\text { weight }\end{array}$ & 2.24 & $2.31 \mathrm{ab}$ & $2.02 \mathrm{c}$ & $2.50 \mathrm{a}$ & $2.11 b c$ \\
\hline وزن صد دانه (گرم) & 100 grain weight (g) & 38.43 & $37.80 \mathrm{a}$ & $40.08 \mathrm{a}$ & $36.08 \mathrm{a}$ & $39.76 \mathrm{a}$ \\
\hline طول دانه (ميلى متر) & $\begin{array}{c}\text { Grain length } \\
\text { Mm }\end{array}$ & 23.56 & $24.12 \mathrm{a}$ & $23.23 \mathrm{ab}$ & $22.36 b$ & $24.52 \mathrm{a}$ \\
\hline عرض دانه (ميلى متر) & $\begin{array}{l}\text { Grain width } \\
\quad(\mathrm{mm})\end{array}$ & 17.77 & $17.82 \mathrm{ab}$ & $18.21 \mathrm{a}$ & $17.77 \mathrm{ab}$ & $17.27 \mathrm{c}$ \\
\hline نسبت طول به عرض & $\begin{array}{c}\text { Grain length/ Grain } \\
\text { weight }\end{array}$ & 1.33 & $1.36 \mathrm{a}$ & $1.28 \mathrm{~b}$ & $1.26 \mathrm{~b}$ & $1.42 \mathrm{a}$ \\
\hline عملكرد غلاف (كرم) & $\begin{array}{l}\text { Pod yield } \\
\quad(\mathrm{g})\end{array}$ & 620.12 & $607.38 b c$ & $629.82 b$ & $533.09 \mathrm{c}$ & $893.52 \mathrm{a}$ \\
\hline عملكرد دانه (كرم) & $\begin{array}{l}\text { Grain yield } \\
(\mathrm{g})\end{array}$ & 1034.73 & $1017.37 \mathrm{bc}$ & $1047.86 a b$ & $893.52 c$ & $1180.18 \mathrm{a}$ \\
\hline 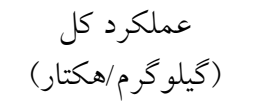 & Total yield (kg\ha) & 414.61 & 409.99ab & $418.03 \mathrm{ab}$ & $360.42 c$ & $469.98 \mathrm{a}$ \\
\hline
\end{tabular}

شماره رُنوتيب

NO. of genotype

16.00

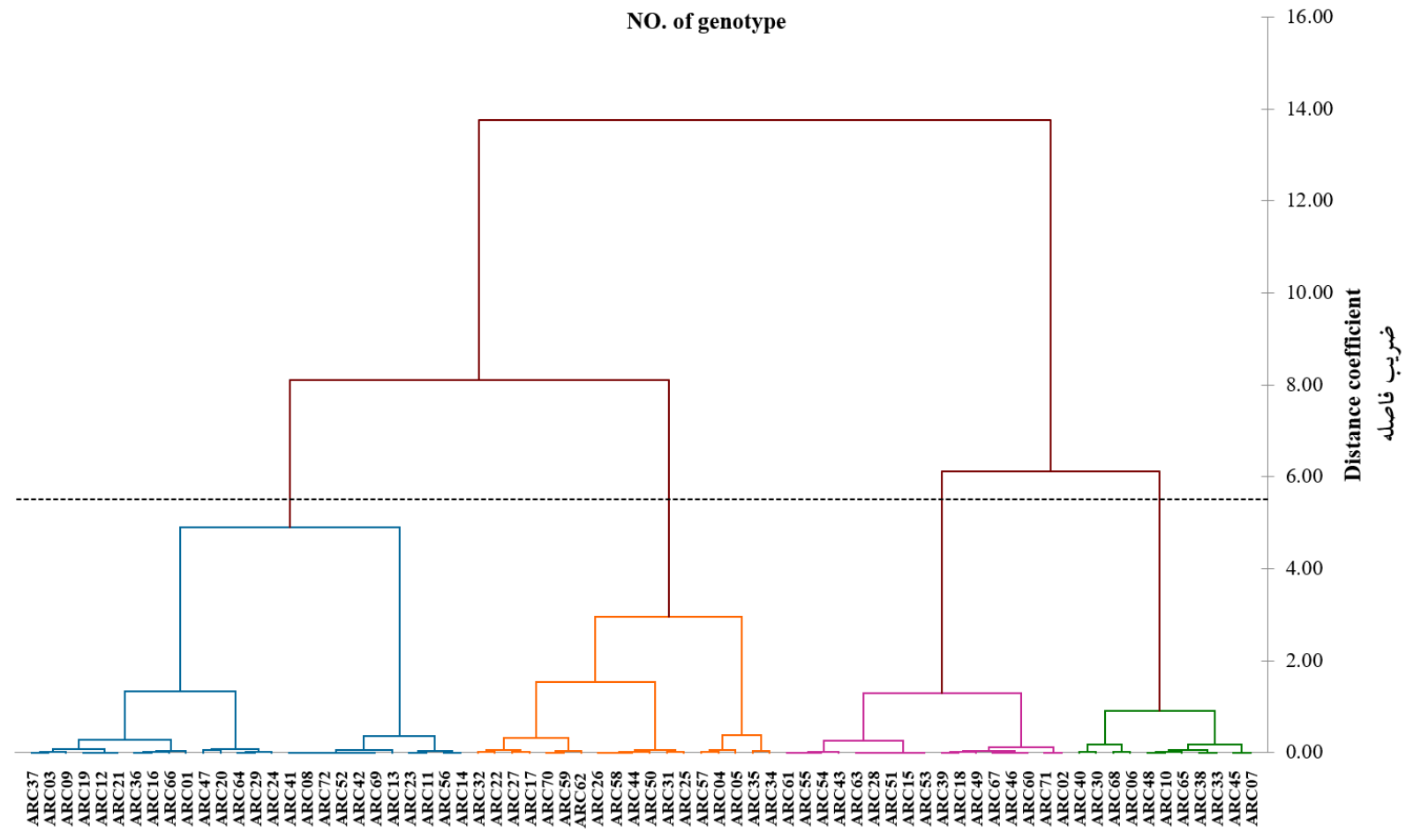

شكل 1- دندوكرام زنوتيبهاى بادام زمينى مورد مطالعه بر اساس روش حداقل واريانس وارد

Figure 1. Dendrogram for peanut genotypes based on ward least variance method 


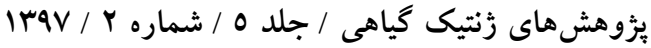

\section{References}

Aalami, A., Abdollahi Mandoulakani, B., Esfahani, M. and Mozaffari, J. (2007). Assessment of genetic diversity in groundnut (Arachis hypogea L.) germplasm using morphological traits. Iran. Journal. Crop Science, 8: 357-367 (InPersian).

Badigannavar, A.M., Kale, D.M. and Murty, G.S.S. (2002). Genetic base and diversity in groundnut genotypes. Plant Breeding, 121: 348-355.

Bhargavi, G., Rao, V., Babu, D., Rao, K. (2017). Character association and path coefficient analysis of pod yield and yield components in Virginia bunch groundnut (Arachis hypogaea L.). Electronic Journal of Plant Breeding, 8: 262-268.

Burton, G.W. and Devane, E. (1953). Estimating heritability in tall fescue (Festuca arundinacea) from replicated clonal material. Agronomy Journal, 45: 478-481.

Dewey, D.R. and Lu, K. (1959). A correlation and path-coefficient analysis of components of crested wheatgrass seed production. Agronomy journal, 51: 515-518.

Dwivedi, S.L., Gurtu, S., Chandra,S., Yuejin, W. and Nigam, S.N. (2001). Assessment of genetic diversity among selected groundnut germplasm. I: RAPD analysis. Plant Breeding, 120: 345-349.

Ebrahimi, M.A., Mohammadian, R. and Khalili, M. (2016). Estimation of Genetic Correlation, Heritability and Grouping of Barley Doubled Haploid Lines Based on Indicators Related to Germination Under Salt Stress. Plant Genetic Researches, 3(1): 29-44.

Foundra, M.Z., Hernandez, M., Lopez, R., Fernandez, L., Sanchez, A., Lopez, J. and Ravelo, I. (2000). Analysis of the variability in collected peanut (Arachis hypogea L.) cultivars for the establishment of core collections. PGR Newsletter, 137: 9-13.

Holbrook, C.C. and Dong, W. (2005). Development and evaluation of a minicore collection for the U.S. peanut germplasm collection. Crop Science, 45: 1540-1544.

Holbrook, C.C. and Stalker, H.T. (2003). Peanut Breeding and Genetic Resources. Plant Breeding Reviews, 22: 297-328.

Hilu, K.W. and Stalker, H.T. (1995). Genetic relationships between peanut and wild species of Arachis sect. Arachis(Fabacea): Evidence from RAPDs. Plant Systematic and Evolution, 198: 167178.

Janila, P., Nigam, S.N., Pandey, M.K., Nagesh, P. and Varshney, R.K. (2013). Groundnut improvement: use of genetic and genomic tools. Frontier Plant Science, 4: 23. doi: 10.3389/fpls.2013 .00023. PMCID: PMC3580887.

Krapovickas, A. and Gregory, W.C. (1994). Taxonomy of the genus Arachis (Leguminosae). Bonplandia, 8:1-186.

Lu, L., Pan, R.Z. and Demski, J.W. (1988). Analysis of diversity in groundnut. In: Reddy, P. S. (Ed). Groundnut. Indian Council of Agriculture Research, New Dehli, IN.

Nasiri, F. (2001). Oil Crop. Astan Quds Razavi Publication, Mashhad, IR (In Persian).

Nikoseresht, R. and Najafian. G. (2016) Genetic diversity and heritability for the selection in bread Wheat lines in Kermanshah. Journal of Plant Genetic Researches, 3(1): 75-88 (In Persian).

Sadeghi, S.M. Javid, F. and Noorhosseini Niyaki, S.A. (2011) Assessment of genetic diversity in peanut (Arachis hypogaea L.) genotypes using quantitative traits by cluster analysis method. Research Journal of Biological Sciences, 6: 293-297.

Soomro, B. and Larik. A.S. (1981). Inheritance and correlation of pod and seed characters in peanuts. Genetica Agraria, 35: 263-264.

Upadhyaya, H.D. (2003). Phenotypic diversity in groundnut (Arachis hypogaea L.) core collection assessed by morphological and agronomical evaluations. Genetic Resources and Crop Evolution, 50(5): 539-550.

Upadhyaya, H.D., Ortiz, R., Bramel P.J. and Singh, S. (2003). Development of a groundnut core collection using taxonomical, geographical and morphological descriptors. Genetic Resources and Crop Evolution, 50: 139-148.

Vange, T. and Maga, T. J. (2014). Genetic characteristics and path coefficient analysis in ten groundnut varieties (Arachis hypogaea L.) evaluated in the Guinea Savannah agro-ecological zone. African Journal of Agricultural Research, 9: 1932-1937.

Varisai-Muhammad, S., Ramanathan, T. and Ramachandran, M. (1975). Variation in pod weight of Arachis hypogaea. Plant Breeding, 45: 378.

Zongo, A., Nana, A.T., Sawadogo, M., Konate, A.K., Sankara, P., Ntare, B.R., Desmae, H. (2017). Variability and Correlations among Groundnut Populations for Early Leaf Spot, Pod Yield, and Agronomic Traits. Agronomy, 7(52): 2-11. 


\title{
Assessment of Genetic Diversity among Peanut (Arachis hypogea L.) Germplasm Using Morphological Traits
}

\author{
Mahtab Samadi Gorji ${ }^{1, *}$, Ali Zaman Mirabadi', Kambiz Forozzan² \\ and Mostafa Haghpanah ${ }^{1}$
}

1-M.Sc., Applied Research and Seed Production center, Oilseeds Research and Development Company, Sari, Iran

2-M.Sc., Applied Research and Seed Production center, Oilseeds Research and Development Company, Tehran, Iran

(Received: September 28, 2017 - Accepted: November 20, 2018)

\begin{abstract}
This experiment was conducted to evaluate genetic diversity in 72 peanut accessions (Arachis hypogaea L.), which introduced from seed bank of Australia in training and seed production research center of oilseeds company, Iran. Twelve major morphological traits recorded during 2013 growing season using a randomized complete block design with three replications. The results showed that the difference between genotypes for all traits was significant. In addition, coefficient of phenotypic variation was greater than coefficient of genotypic variation for all traits, indicating the effect of environment on recorded traits. The broad-sense heritability ranged from $80.25 \%$ (for seed width) to $99.54 \%$ (for 100 seed weight) and was $96.85 \%$ for grain yield. The highest phenotypic and genotypic coefficients of variation obtained for the pod weight, thus, it is possible to improve this trait by selection method and this trait could use as a selection index to improve grain yield. Genetic correlation indicated a high significant correlation between grain yield with grain weight and pod yield. The studied genotypes divided to four groups by cluster analysis based on Ward method.
\end{abstract}

Keywords: Peanut, Cluster analysis, Genetic diversity, Morphological traits 